\title{
British drive for more women in science
}

[LONDON] Britain's science minister, Lord David Sainsbury, last week launched a project to promote women in science that has the long-term goal of seeing the same proportion of women in academic appointments as those recruited as undergraduates.

The varied strategy of the so-called Athena Project includes collecting and disseminating statistics, fostering personal and organizational development by raising the awareness of good practice in human resources, and facilitating and funding initiatives and awards.

Over the next four years, Athena aims to help achieve a 10 per cent increase in the number of women recruited to all levels of the academic community. In one project, higher education institutions will be invited to bid for grants for projects designed to improve the participation and promotion of women in science, engineering and technology, and to develop good practice.

Launching the project, Sainsbury said the British government was "well aware that we are not using all the available talent, and that the skill pool from which we draw our brightest academics could be enhanced by drawing on the wider pool of talented women".

A register of women in higher education, analysing their education, qualifications, positions and salaries, will form an important part of the project. Initially focusing on data for women in science, engineering and technology, the scheme will offer services

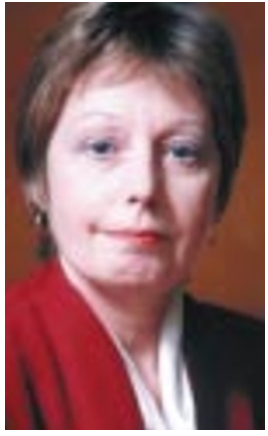

Bullivant: seeking the support of industry. address issues such as training, career breaks, promotion and the profile of women in higher education.

Those responsible for launching the project acknowledge that the goodwill of the senior university managers, academics, politicians and industrialists who attended last week's meeting will need to be backed up by more money.

In addition to an initial $£ 100,000$ (US\$160,000) for the first year, newly appointed project director Susan Bullivant needs to find at least as much again.

Core funding currently comes from higher education and the government, but industry and learned societies are high on Athena's list of potential sources of additional funding.

Bullivant says she is looking for organizations that may share Athena's objectives. "We might be able to help them in their strategic aims," she says.

Changing attitudes, cultures and practices within universities will not be easy. "It has to be done in a consultative and collaborative way," says Bullivant, who argues that the issue is about best practice in human resources, and so obtaining the best people irrespective of gender.

"An organization with a quality reputation is one where staff and students want to go," says Bullivant. "So the role of getting women is linked to major drives in the sector — to get the best people.” Brian Fender, chief executive of the Higher Education Funding Council for England, agrees: "Our motive is that we want the best possible progression of education."

Athena builds on earlier work by the Scottish Higher Education Funding Council, which produced a series of guides to best practice in three key areas of women's involvement in academic science, engineering and technology: their access, participation and progress. The guides included details of successful projects and pilot studies in areas of concern.

One of the studies followed mentoring pairs at the University of Edinburgh, and concluded that mentoring increased assertiveness and networking skills in those being mentored, with both parties demonstrating increased confidence. One of Athena's aims will be to help establish mentoring schemes.

Natasha Loder

\section{Indian budget boost targets innovation, vac c ines and genetic s}

[NEW DELHI] Funding for Indian science is to be increased next year to US $\$ 2.44$ billion 3.6 per cent of the total national budget under proposals submitted by the Bharatiya Janata Party government to parliament last week.

The government also announced three new schemes: a national fund for promoting innovation, a technology mission on vaccines, and the creation of a national bioresources board to conserve and manage India's genetic resources.

The science budget does not include $\$ 399$ million allocated for nuclear-power construction projects, including the development of a prototype fast-breeder reactor. "There is an increase in funding, though not substantial, and scientists are happy," says Valangiman Ramamurthi, secretary to the Department of Science and Technology.

As in the past, the three 'strategic' departments of defence, atomic energy and space get the lion's share ( 51 per cent) of the money (see Table 1). The Space Department, which is developing a large cryogenic rocket engine, a second launch pad, and a highpower direct broadcasting satellite, gets an increase of 16 per cent. All increases are calculated over the final 1998-99 figures, rather than the significantly higher budget figures initially proposed.

The 32 per cent increase in the atomicenergy budget includes funds for advanced

\begin{tabular}{lcc}
\hline Table 1 Proposed Indian s cience budget for \\
1999- 2000 (in US \$ million)
\end{tabular}

plasma devices and a new national centre for applied mathematics and radio astrophysics, to be set up at the Tata Institute of Fundamental Research in Mumbai (Bombay).

The electronics sector is slated for a 33 per cent increase in research funding, reflecting government emphasis on information technology. Crop research will see its budget grow by 26 per cent.

One of the three new schemes is a national foundation, with an initial fund of $\$ 5$ million, to compile a national register of innovators and to help convert their work into business opportunities.

Finance minister Yashwant Sinha announced the launch of a technology mission to focus on "new vaccines that will revolutionize the medical and health systems".

The proposed national bioresources board, to be headed by the minister for science, will coordinate "policies, research, documentation and legal protection" of the country's genetic wealth.

K.S.Jayaraman 